\title{
Idiopathic acute fatty liver of pregnancy
}

\author{
K. J. BREEN, K. W. PERKINS, S. P. MISTILIS, AND R. SHEARMAN \\ From the A. W. Morrow Department of Gastroenterology, Royal Prince Alfred Hospital, and King \\ George V Memorial Hospital for Mothers and Babies, Missenden Road, Camperdown, \\ New South Wales, Australia
}

SUMMARY A maternal survivor of idiopathic fatty liver, with the characteristic histological appearance on liver biopsy, is reported. Profound hypoglycaemia was the major complication in this patient and it is suggested that more attention should be given to the blood glucose in this disease. The consideration of future pregnancy in this patient is discussed.

Idiopathic acute fatty liver of pregnancy is a rare and usually fatal condition with characteristic liver histology. In this case report a further survivor is described emphasizing the major problem encountered in management, namely, severe hypoglycaemia and the question of future pregnancies.

\section{Case Report}

The patient, a 23-year-old woman, was admitted to hospital in the thirty-seventh week of pregnancy, complaining of nausea, vomiting, and drowsiness for four days. Spontaneous labour commenced the next day and stillborn twins were delivered 12 hours later. Thirteen hours after delivery the Received for publication 25 May 1970.

\begin{tabular}{|c|c|c|c|c|c|}
\hline Day & $\begin{array}{l}\text { Serum } \\
\text { Bilirubin } \\
(\mathrm{mg} / 100 \mathrm{ml})\end{array}$ & $\begin{array}{l}\text { Serum } \\
\text { Alkaline } \\
\text { Phosphatase } \\
(\text { KA units } / \\
100 \mathrm{ml})\end{array}$ & $\begin{array}{l}\text { Serum Glutamic } \\
\text { Oxaloacetic } \\
\text { Transaminase } \\
\text { (Sigma Frankel } \\
\text { units } / 100 \text { ml) }\end{array}$ & $\begin{array}{l}\text { Concentration } \\
\text { of Blood } \\
\text { Glucose } \\
(\mathrm{mg} / 100 \mathrm{ml})\end{array}$ & $\begin{array}{l}\text { Total Leucocyte } \\
\text { Count }\left(\mathrm{mm}^{3}\right)\end{array}$ \\
\hline 7 & 7.9 & - & 42 & - & 34,000 \\
\hline 10 & $7 \cdot 4$ & 70 & 67 & 10 & 30,400 \\
\hline 11 & 5.9 & 50 & 104 & 75 & 26,100 \\
\hline 12 & $5 \cdot 0$ & 50 & 75 & 76 & 21,000 \\
\hline 16 & $3 \cdot 5$ & 12 & 55 & 106 & - \\
\hline 23 & $1 \cdot 3$ & 27 & 45 & 100 & 9,800 \\
\hline 90 & 0.7 & - & 20 & - & 7,500 \\
\hline
\end{tabular}

Table Serial biochemistry and leucocyte counts commencing on the seventh day after the onset of symptoms patient had a generalized convulsion. Jaundice was then noticed. Initial investigations taken six days after the onset of symptoms are recorded in the Table. The patient remained mildly jaundiced and semicomatose for the next three days when she was transferred to the authors' hospital.

There had been one normal pregnancy two years previously and the present pregnancy had been observed regularly and had progressed normally until the thirty-seventh week. There was no history of drug ingestion or contact with hepatitis. Physical examination revealed a well nourished, jaundiced, unconscious female. The temperature and pulse were normal and blood pressure was $170 / 100 \mathrm{~mm}$ mercury. The liver edge was palpable $3 \mathrm{~cm}$ below the costal margin. Minimal peripheral oedema was present. The level of serum bilirubin was $7.4 \mathrm{mg} / 100 \mathrm{ml}$ and serum alkaline phosphatase was 70 King Armstrong units $/ 100 \mathrm{ml}$. Serum glutamic oxaloacetic transaminase was 67 Sigma Frankel units $/ 100 \mathrm{ml}$, the blood urea was $52 \mathrm{mg} / 100 \mathrm{ml}$, haemoglobin was $12 \cdot 2 \mathrm{~g} / 100 \mathrm{ml}$, leucocyte count 30,400 per $\mathrm{mm}^{3}$ ( $73 \%$ neutrophils), and the blood film showed vacuolated neutrophils, target cells, and burr cells.

The prothrombin index was $50 \%$ of normal and rose to $70 \%$ of normal in 12 hours following parenteral vitamin K. A percutaneous liver biopsy was performed without complication and showed the typical appearances of acute fatty liver of pregnancy (Fig.). Blood glucose concentration on admission was $10 \mathrm{mg} / 100 \mathrm{ml}$. Intravenous administration of dextrose $(75 \mathrm{~g})$ was followed by marked improvement in mental state, such that the 


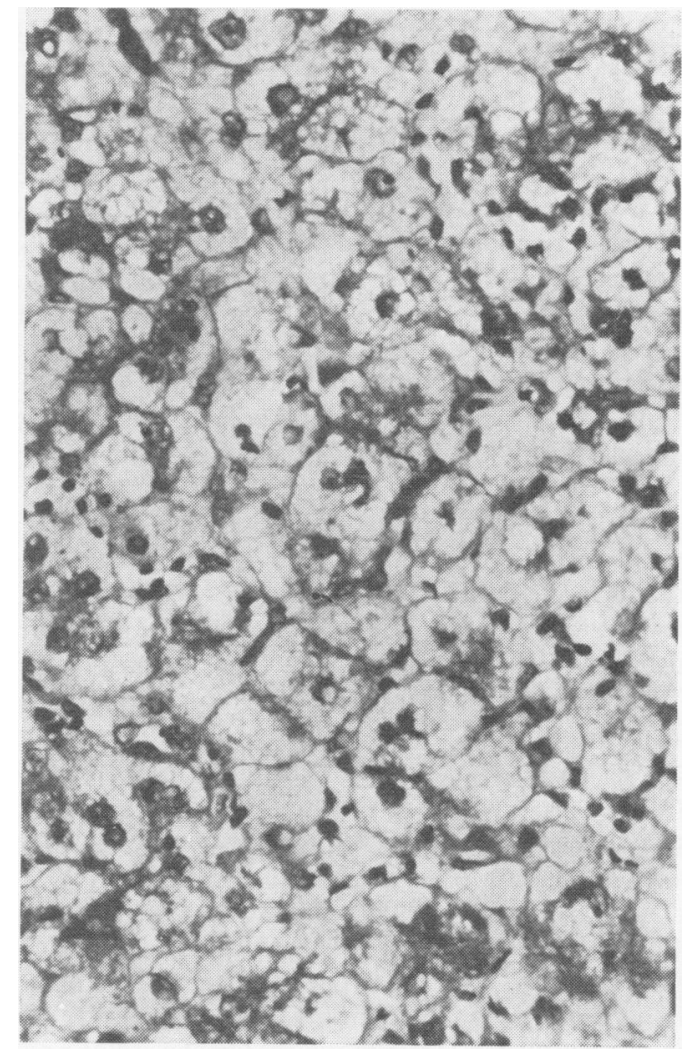

Fig. The hepatocytes are distended by multiple small vacuoles containing fat which stains with Sudan III. The nuclei are central. (Haematoxylin and eosin, $\times 800$.)

patient was able to converse. She became drowsy twice in the next 24 hours but improved with increased dextrose administration. Clinical improvement continued and intravenous dextrose was ceased after 154 hours. No further complications ensued and the biochemical abnormalities gradually returned to normal (Table). A liver biopsy at three weeks showed considerable improvement and a further biopsy at three months was normal. After 10 months the patient was physically well and had normal liver function tests.

\section{Discussion}

Although first described by Stander and Cadden in 1934, it was Sheehan in 1940 who recognized and first defined the typical histology of this condition which he called 'obstetrical acute yellow atrophy'. Subsequently terminology has varied (Ober and le Compte, 1955) but the term 'acute fatty liver of pregnancy' (Moore, 1956) is favoured by the authors. The occurrence of an identical clinical picture following the intravenous administration of tetracycline to pregnant women is well documented (Kunelis, Peters, and Edmonson,
1965). Whether the histological changes after tetracycline are identical to those of acute fatty liver of pregnancy has been questioned (Schultz, Adamson, Workman, and Norman, 1963; Iber, 1965); hence the diagnosis should be qualified as 'idiopathic' or 'tetracycline associated', as first suggested by Kunelis et al (1965).

The first documented survivor of idiopathic fatty liver was reported in 1942 (Whiteacre and Fang). The total number of cases and maternal survivors recorded in the literature varies with the diagnostic criteria applied. Thus, Kunelis et al (1965) who included tetracycline-associated cases, listed 54 patients of whom 10 survived. Iber (1965) found 46 cases and seven survivors and Haemmerli (1966) found 40 cases with six survivors; both these authors excluded patients given tetracycline. Only six infants have survived (Joske, McCully, and Mastaglia, 1968). Acute fatty liver is one of the least common entities in the major series of jaundice in pregnancy."(Sheehan, 1961; Siegler and Keyser, 1963; Haemmerli, 1966).

Reported cases have strikingly similar clinical features, occurring in mothers of widely varying ages, commonly in the first or second pregnancy. The illness usually commences after the thirtysixth week with the relatively sudden onset of nausea, vomiting, and epigastric pain, followed by jaundice and drowsiness. In most cases, spontaneous labour ensues with delivery of a stillborn infant and subsequent deterioration of the mother with death from hypoglycaemia, shock, metabolic acidosis, hepatic failure, or renal failure.

Severe hypoglycaemia has been overlooked as a major complication of acute fatty liver. Early reports (Stander and Cadden, 1934; Whitacre and Fang, 1942) mention this risk but blood glucose concentrations have rarely been mentioned by recent reviewers (Schultz et al, 1963; Duma, Dowling, Alexander, Sibrans, and Dempsey, 1965; Kunelis et al, 1965; Giles, 1967; Morrin, Handa, Valberg, Benscosme, Kipkie, and Wyllie, 1967; Joske et al, 1968). Coma has been the most common mode of death in reported cases and is usually attributed to hepatic failure, or less commonly to renal failure or shock (Ober and le Compte, 1955; Sheehan, 1961). In a few cases coma has followed progressive severe hyperbilirubinaemia, bleeding, and a clinical picture typical of massive liver necrosis. However in most cases the bilirubin level remains less than 10 $\mathrm{mg} / 100 \mathrm{ml}$ (Haemmerli, 1969) and coma has occurred without a clinical course typical of severe hepatic failure (Haemmerli, 1966). Azotaemia is usually moderate and related to dehydration or shock, although fatty vacuolation of renal tubular cells has been reported (Ober and le Compte, 1955). In many cases coma has appeared extremely rapidly, before the onset of hypotension or renal failure, and in the majority of patients has not been adequately explained. It is suggested that 
coma in these cases is the result of hypoglycaemia. Experience in the present case indicates that the blood glucose concentration requires frequent monitoring and that large quantities of dextrose are needed to maintain normal levels.

Other complications have included haemorrhage of the upper gastrointestinal tract and acute pancreatitis, the latter clinically unsuspected and found at necropsy. The clinical status of the six surviving infants has not been reported in depth and few details are available regarding the state of the liver in the stillborn infants. On two occasions the foetal liver has not shown marked fatty change (Lewis, Takeda, and Warren, 1963; Giles, 1967).

The histological appearances in acute fatty liver of pregnancy are distinctive and diagnostic. The features shown in the Figure are representative. The hepatocytes are distended and have a foamy appearance, which on staining can be shown to be due to fat distributed in multiple vacuoles about a central nucleus. Periportal hepatocytes are often spared this process, a feature thought by some authors to distinguish the idiopathic condition from tetracycline-associated fatty liver (Iber, 1965; Kunelis et al, 1965; Giles, 1967).

There is no disturbance of hepatic architecture, and cell necrosis and inflammation are unusual. In most reported cases this histology has been reported only at necropsy. The serial liver biopsies in the present case confirm the previously published observations on the rate and degree of histological recovery, showing return to normal within three months (Duma et al, 1965).

The pathogenesis is unknown and many theories have been advanced to explain the aetiology of this condition. Administration of ethionine (a methionine antagonist) or deficiency of choline can each cause a similar appearance in experimental animals (Goldberg and Chaikoff, 1951; Hutterer, Fitschen, and Popper, 1961; Kunelis et al, 1965) but there is no convincing evidence that nutritional deficiency has been a factor in reported cases of acute fatty liver of pregnancy. The role of tetracycline has been mentioned above and is discussed in detail by Schultz et al (1962) and Kunelis et al (1965). No other drugs have been implicated. It has been suggested that a usually fatal childhood illness resembling acute fatty liver of pregnancy in many of its clinical features and in its histological appearances may be secondary to viral infection (Reye, Morgan, and Boral, 1963; Barr, Glass, and Chawla, 1968). The possibility that an undetected virus or toxin may cause acute fatty liver has also been mentioned by other workers (Whitacre and Fang, 1942; Iber, 1965; Joske et al, 1968). There is no evidence that acute fatty liver of pregnancy is in any way related to acute yellow atrophy, acute infectious hepatitis, or cholestasis of pregnancy (Sheehan, 1961; Haemmerli, 1966). Preeclamptic toxaemia has been present in a minority of cases, insufficient to suggest that it is a predisposing condition (Iber, 1965).

On the basis of a small number of maternal survivors in whom Caesarean section or induction of labour appeared to bring about improvement, several writers have suggested that immediate termination of pregnancy is advisable (Ober and le Compte, 1955; Iber, 1965). However others have expressed doubt that termination improves maternal survival rates (Kunelis et al, 1965; Giles, 1967). Foetal survival figures may be improved by immediate termination as the condition usually presents after 36 weeks of gestation when the foetus is viable. The majority of maternal survivors have been treated with symptomatic measures alone (Sheehan, 1961; Peters, Edmonson, and Kunelis, 1962; Siegler and Keyser, 1963). Specific therapeutic agents, including choline chloride (Moore, 1956), steroids (Recant and Lacy, 1963; Woolf, Johnston, Stokes, and Robertson, 1964), and methionine (Faloon, 1954), have been used without convincing evidence of benefit. The supportive measures to be employed are well reviewed by Iber (1965) but the anticipation and treatment of hypoglycaemia warrants reemphasis.

The question of further pregnancy in survivors of acute fatty liver was not discussed in previous case reports or reviews and there is no recorded recurrence of acute fatty liver in subsequent pregnancies. On the other hand, Moore (personal communication) has recorded one survivor followed through a subsequent uncomplicated pregnancy. This information indicates that the risk of recurrence is a relative rather than an absolute contraindication to subsequent pregnancy. The patient reported here is anxious to have further children, and, should pregnancy ensue, it is intended to monitor liver function closely and to consider elective termination of pregnancy at 36 weeks' gestation.

The authors wish to acknowledge the kind assistance of Dr J. Beith, Dubbo, New South Wales, and Dr V. J. McGovern, Fairfax Institute of Pathology, Royal Prince Alfred Hospital.

\footnotetext{
References

Barr, R., Glass, I. H. J., and Chawla, G. S. (1968). Reye's syndrome: massive fatty metamorphosis of the liver with acute encephalopathy. Canad. med. Ass. J., 98, 1038-1044.

Duma, R. J., Dowling, E. A., Alexander, H. C., Sibrans, D., and Dempsey, H. (1965). Acute fatty liver of pregnancyreport of a surviving patient studied with serial liver biopsies. Ann. Intern. Med., 63, 851-858.

Dyson, B. C. (1959). Fatty metamorphosis of the liver in pregnancy. Bull. Ayer clin. Lab., 4, 17-30.

Faloon, W. W. (1954). Metabolic and histologic studies in patients with and without liver disease receiving chloramphenicol and oxytetracycline. J. Lab clin. Med., 44, 75-90.

Giles, P. F. H. (1967). Obstetric acute yellow atrophy. Aust. N.Z.J. Obstet. Gynaec., 7, 18-24.

Goldberg, R. C., and Chaikoff, I. L. (1951). Selective pancreatic acinar destruction by dl-ethionine. Arch. Path., 52, 230-243.
} 
Haemmerli, U. P. (1966). Jaundice during pregnancy-with special emphasis on recurrent jaundice during pregnancy and its differential diagnosis. Acta med. scand., Suppl. 444.

Haemmerli, U. P. (1969). Jaundice during pregnancy. In Diseases of the Liver, edited by L. Schiff, 3rd ed., chapter 30, pp. 1023-1036. Lippincott, Philadelphia and Toronto.

Hutterer, F., Fitschen, W., and Popper, H. (1961). Mitochondrial damage and hepatic steatosis in ethionine intoxication. Brit. J. exp. Path., 42, 187-194.

Iber, F. L. (1965). Jaundice in pregnancy-a review. Amer. J. Obstet. Gynec., 91, 721-753.

Joske, R. A., McCully, D. J., and Mastaglia, F. L. (1968). Acute fatty liver of pregnancy. Gut, 9, 489-493.

Kunelis, C. T., Peters, J. L., and Edmondson, H. A. (1965). Fatty liver of pregnancy and its relationship to tetracycline therapy. Amer. J. Med., 38, 359-377.

Lewis, P. L., Takeda, M., and Warren, W. J. (1963). Obstetric acute yellow atrophy-report of a case. Obstet. and Gynec., 22, 121-127.

Moore, H. C. (1956). Acute fatty liver of pregnancy. J. Obstet. Gynaec. Brit. Emp., 63, 189-198.

Morrin, P. A. F., Handa, S. P., Valberg, L. S., Benscosme, S. A Kipkie, G. F., and Wyllie, J. C. (1967). Acute renal failure in association with fatty liver of pregnancy-Recovery after 14 days of complete anuria. Amer. J. Med., 42, 844-851.

Ober, W. B., and le Compte, P. M. (1955). Acute fatty metamorphosis of the liver associated with pregnancya distinctive lesion. Amer. J. Med., 19, 743-758.
Peters, R. L., Edmondson, H. A., and Kunelis, C. T. (1962). Second multiple discipline research forum: presentation no. 68. Acute fatty metamorphosis of the liver in pregnancy (Excerpt). J. Amer. med. Ass., 180, 767.

Recant, L., and Lacy, P. (1963). Fulminating liver disease in a pregnant woman at term. Amer. J. Med., 35, 231-240.

Reye, R. D. K., Morgan, G., and Baral, J. (1963). Encephalopathy and fatty degeneration of the viscera-a disease entity in childhood. Lancet, 2, 749-752.

Schultz, J. C., Adamson, J. S., Workman, W. W., and Norman, T. D. (1963). Fatal liver disease after intravenous administration of tetracycline in high dosage. New Engl. J. Med., 269, 999-1004.

Sheehan, H. L. (1940). The pathology of acute yellow atrophy and delayed chloroform poisoning. J. Obstet. Gynaec. Brit. Emp., 47, 49-62.

Sheehan, H. L. (1961). Jaundice in pregnancy. Amer. J. Obstet. Gynec., 81, 427-440.

Siegler, A. M., and Keyser, H. (1963). Acute hepatitis in pregnancy. Amer. J. Obstet. Gynec., 86, 1068-1073.

Stander, H. J., and Cadden, J. F. (1934). Blood chemistry in preeclampsia and eclampsia. Amer. J. Obstet. Gynec., 28, 856-871.

Whitacre, F. E., and Fang, L. Y. (1942). Fatty degeneration of the liver in pregnancy. Report of a case with recovery: chemical and histologic studies. J. Amer. med. Ass., 118, 1358-1364.

Woolf, A. J., Johnston, A. W., Stokes, J. F., and Robertson, N. R. C. (1964). Acute liver failure in pregnancy. Case report with survival of mother and child. J. Obstet Gynaec. Brit. Cwlth., 71, 914-918. 